\title{
La genética en la medicina actual: problemas que plantean los test genéticos de consumo difundido
}

\author{
Genetics in current medicine: problems laid out by widely-used \\ genetic tests
}

Ruíz-de-Almirón-de-Andrés, B.

Estudiante de la Facultad de Medicina. Universidad de Granada. Máster en Abogacía. Universidad de Granada.

\section{Estimado Editor:}

Laín Entralgo afirmaba que la medicina actual está representada por la tecnificación instrumental, la colectivización, la personalización del enfermo, la prevención de la enfermedad y la promoción de la salud (1). Actualmente, los avances en el conocimiento del genoma humano y la evidencia de genes vinculados al desarrollo de enfermedades han dado lugar a nuevos métodos para mejorar la prevención y curación de ciertas enfermedades. Además, en la actualidad, se habla también de epigenética, la cual supone una alteración en la expresión génica del ADN sin afectar a la secuencia. La medicina genómica emplea diferentes tipos de análisis genéticos con el fin de detectar la presencia o la ausencia de variantes en segmentos de material genético. Esta metodología permite detectar productos génicos o metabolitos específicos indicativos de un cambio genético concreto (2).

Dentro de los test genéticos existentes, distinguimos tres tipos: de diagnóstico, de tratamiento y de predicción o consumo difundido. Los primeros, son empleados en el marco de una consulta médica con el fin de diagnosticar precozmente una enfermedad genética, en presencia o ausencia de síntomas. Los segundos, se adaptan a las características del paciente. Los terceros, por último, los solicita el consumidor sin prescripción médica, generalmente a través de Internet y plantean algunas cuestiones legales y sociales. Sus características principales son: solicitud directa del consumidor a la compañía, frecuentemente en ausencia de una enfermedad diagnosticada y sin perspectiva de utilidad clínica; ausencia de asesoramiento genético por un facultativo médico; $y$ finalmente, carácter multifactorial y no monogénico, es decir, se genotipan millones de polimorfismos de un solo nucleótido, siendo inespecíficas las pruebas (3).

Existen, por otro lado, empresas que ofrecen una secuenciación del genoma sin exigir un reembolso, pero a cambio de incluir los datos genómicos y médicos de los participantes en bases informáticas (4). Toda la información quedaría en propiedad de la empresa, lo cual podría llevar ocasionalmente a una invasión de la privacidad genética. En España, los test genéticos, regulados por la Ley de Investigación Biomédica, únicamente pueden hacerse con fines médicos o de investigación clínica, asesoramiento genético de un profesional responsable y prescripción médica. También, en el marco legal europeo, se adopta generalmente una delimitación similar.

Respecto a los test genéticos de consumo difundido, no existe regulación específica, pero el Reglamento 1662/2000 sobre productos sanitarios para diagnóstico in vitro, prohíbe la publicidad de productos sanitarios destinados al estudio de muestras procedentes del cuerpo humano como donaciones de sangre y tejidos con un fin de diagnóstico genético (5).

En conclusión, primero, con la importancia de la epigenética en la medicina actual, la condición genética no es determinante, sino un factor más para tener en cuenta. Así, la información genética obtenida con estas pruebas únicamente permite hablar de riesgos o predisposiciones. Segundo, aun teniendo en cuenta el principio de autonomía del paciente, predomina la falta de información al consumidor y la ausencia de asesoramiento genético. Finalmente, la falta de regulación de estos test los dejaría fuera del marco legal y afectando, por tanto, también a su comercialización.

\section{REFERENCIAS BIBLIOGRÁFICAS}

1. Laín Entralgo P. La medicina actual. Seminarios y Ediciones, S.A. 1973.

2. Ley $14 / 2007$, de 3 de julio, de Investigación Biomédica (BOE, 4 de julio de 2007). 2007 p. 28826-48.

3. Bunnik EM, Schermer MHN, Janssens ACJ. Personal genome testing: Test characteristics to clarify the discourse on ethical, legal and societal issues. BMC Med Ethics. 2011;12(1).

4. Genetics Start-Up Wants to Sequence People's Genomes for Free - Scientific American [Internet]. [cited 2020 Jul 5]. Available from: https://www.scientificamerican.com/article/geneticsstart-up-wants-to-sequence-peoples-genomes-for-free/

5. Real decreto $1662 / 2000$, de 29 de septiembre, obre productos sanitarios para diagnóstico "in vitro." Vol. núm. 268, Boletín Oficial del Estado (BOE). 2009. 